\title{
Cistolitectomia para tratamento de cistolitíase em coelho doméstico (Oryctolagus cuniculus): relato de caso
}

\author{
[Cistolitectomy for the treatment of cystolithiasis in domestic rabbit \\ (Oryctolagus cuniculus): case report]
}

\section{"Relato de Caso/Case Report"}

\author{
Claudio Douglas Oliveira Guimarães ${ }^{1 *}$, André Rebelo Pantoja ${ }^{2}$, Aline Lobão da Silva ${ }^{2}$, Dandara \\ Vitoria Alves Dias ${ }^{2}$, Bianca Mendonça Faria ${ }^{2}$, Maridelzira Betânia Moraes David ${ }^{3}$, Luiz Fernando \\ Moraes Moreira ${ }^{3}$
}

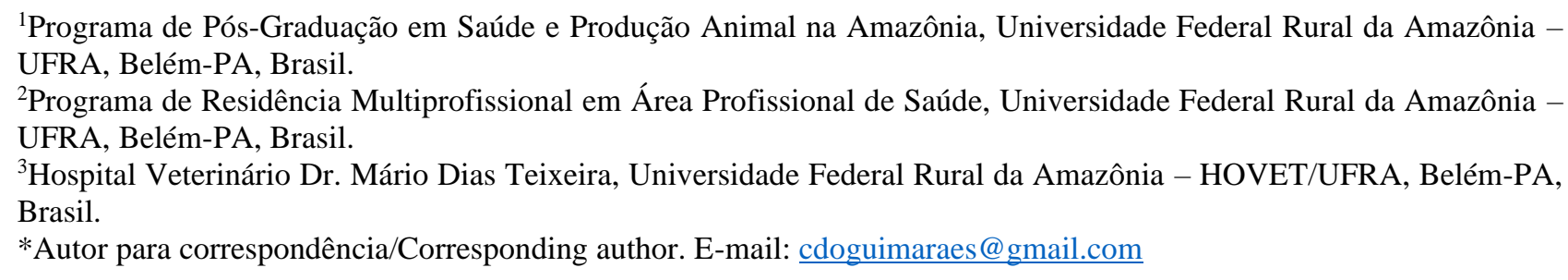

\section{Resumo}

A formação de urólitos em coelhos domésticos (Oryctolagus cuniculus) é uma ocorrência comum na Medicina Veterinária de Lagomorfos, em parte favorecida pela elevada concentração de cristais na composição da urina associada a uma dieta rica em minerais e pouca ingestão hídrica. Este trabalho tem como objetivo relatar um caso de cálculo vesical nesta espécie enfatizando terapia clínica e cirúrgica do caso. Foi atendido no Hospital Veterinário da Universidade Federal Rural da Amazônia um coelho doméstico tendo como principais queixas a presença de sangue na urina, perda progressiva de apetite e interesse hídrico. Durante o exame clínico foi observada presença de estrutura firme em região abdominal, a qual, após realização de exames de imagem, foi identificada como sendo um cálculo vesical. A partir disso, foi realizado tratamento clínico e cistolitectomia para retirada do urólito, seguida de adequação da dieta. O manejo clínico-cirúrgico adotado neste caso mostrouse eficaz para a boa recuperação do paciente.

Palavras-chave: urologia; cistite; lagomorfos.

\begin{abstract}
The formation of uroliths in domestic rabbits (Oryctolagus cuniculus) is a common occurrence in the veterinary medicine of Lagomorphs, partly favored by the high concentration of crystals in the urine composition associated with a diet rich in minerals and low water intake. This study aims to report a case of bladder calculus in this species emphasizing clinical and surgical therapy of the case. A domestic rabbit was attended at the Veterinary Hospital of the Federal Rural University of the Amazon, the main complaints being the presence of blood in the urine, progressive loss of appetite and water interest. During the clinical examination, a firm structure was observed in the abdominal region, which, after performing imaging tests, was identified as a bladder stone. From this, clinical treatment and cystolitectomy were performed to remove urolith followed by diet adequacy. The clinical-surgical management adopted in this case proved to be effective for the good recovery of the patient.
\end{abstract}

Keywords: urology; cystitis; lagomorphs.

\section{Introdução}

A ordem Lagomorpha é representada pelos coelhos, lebres e lebres assobiadoras, sendo nativos Antártida. Ocupam um intervalo entre os roedores e ungulados, sendo considerados por muito tempo 
como roedores, até o reconhecimento da ordem em 1912 (Vilardo, 2007; Chapman e Flux, 2008).

Os coelhos, principalmente o coelho doméstico (Oryctolagus cuniculus) representa grande importância para o homem, provendo recurso alimentar, servindo como modelos animais na pesquisa científica, agregando valor econômico em criações zootécnicas e afetivo, quando domiciliados (Quinton, 2005; Vilardo, 2007; Chapman e Flux, 2008). São herbívoros e apresentam como características a presença de um segundo par de incisivos localizados diretamente atrás dos incisivos dianteiros superiores, com raízes abertas, permitindo um crescimento dentário contínuo. Possuem longas orelhas, cobertura densa de pelos pelo corpo e pelos sensoriais especializados ao redor do focinho e acima dos olhos (Vilardo, 2007; Chapman e Flux, 2008).

Fisiologicamente, a urina dos coelhos é turva e pode variar de vermelho a amarelo-alaranjado devido a um pigmento porfirínico (Carpenter, 2003; Quinton, 2005; Vilardo, 2007). No entanto, uma urina densa e de coloração esbranquiçada pode ser identificada normalmente como resultado de grande quantidade de precipitados minerais presentes principalmente na dieta (HarcourtBrown, 2002; Carpenter, 2003; Quinton, 2005; Vilardo, 2007; Chapman e Flux, 2008). Em alguns casos, quantidades excessivas de carbonato de cálcio ingeridas podem levar a quadros de hipercalciúria com formação de urólitos ou cálculos urinários que, nesta espécie, parece estar mais relacionada à origem metabólica do que infecciosa (Carpenter, 2003; Quinton, 2005; Vilardo, 2007).

Cálculos geralmente são de oxalato de cálcio e ocorrem tanto em machos quanto em fêmeas. Porém, coelhos que apresentam urolitíase são, em geral, obesos, sedentários, alimentados à vontade com ração e frequentemente com história prévia de ingestão de suplementos vitamínicos e minerais. Além disso, o uso abusivo de dieta seca rica em cálcio, consumo insuficiente de água e inflamação crônica das vias urinárias concorrem para a formação de cálculos (Harcourt-Brown, 2002; Carpenter, 2003; Quinton, 2005; Vilardo, 2007; Chapman e Flux, 2008). Embora a agregação dos cristais tenha sido sugerida como principal mecanismo de formação de cálculos em coelhos, a fisiopatogenia ainda não está completamente compreendida e, pode estar relacionada com a interação de vários fatores: dietéticos, anatômicos, ambientais e infecciosos (Redrobe, 2002; Fisher, 2006).

O diagnóstico de urolitíase é feito por meio do histórico, exame clínico e exames complementares, especialmente a radiografia, pela facilidade de visualização dos cálculos (Vilardo, 2007). A dosagem da concentração de cálcio sanguíneo em coelhos que excretam grandes quantidades de cálcio urinário também é uma ferramenta importante para o diagnóstico (Vilardo, 2007). Algumas vezes, cálculos renais, mineralização renal e nefrocalcinose podem estar presentes, sendo essencial a realização de ultrassonografia para avaliação completa do quadro (Quinton, 2005; Vilardo, 2007).

De um modo geral, o tratamento da urolitíase é clínico-cirúrgico e inclui uso de antiinflamatório e antibiótico, fluidoterapia, sondagem uretral e vesical, retirada dos cálculos e adequação no manejo dietético a fim de evitar a recidiva (Quinton, 2005; Vilardo, 2007). Nesse caso, diminuição da quantidade de ração e aumento da quantidade de verduras frescas fornecidas, obedecendo sempre a relação Ca:P na proporção de 1,2 a 1,3, podem auxiliar na profilaxia da doença em coelhos (Carpenter, 2003; Quinton, 2005; Vilardo, 2007; Chapman e Flux, 2008). Em virtude da incomum frequência de cistolitíase em coelho doméstico (Oryctolagus cuniculus) e os poucos dados clínico-cirúrgicos disponíveis na literatura, objetiva-se com este trabalho, relatar um caso de cálculo vesical nesta espécie enfatizando terapia clínica e cirúrgica do caso.

\section{Descrição do Caso}

Um coelho doméstico (Oryctolagus cuniculus) macho, cinco anos de idade, da raça Nova Zelândia, pesando $2,584 \mathrm{~kg}$, foi atendido no ambulatório de animais selvagens anexo ao Hospital Veterinário Professor Mário Dias Teixeira, da Universidade Federal Rural da Amazônia, Belém, Pará no dia 31 de outubro de 2017, tendo como principais queixas a presença de sangue na urina, perda progressiva de apetite e interesse hídrico.

Durante a anamnese verificou-se que o animal foi comprado em feira livre e era mantido solto no quarto da tutora, tendo eventualmente acesso ao quintal. A alimentação era constituída basicamente por ração e folhas de couve-flor, com água sendo fornecida ad libitum. Ao exame clínico, foi observado que o paciente apresentava score corporal regular, pele e anexos sem alterações, grau 
de hidratação normal, mucosa oral, mucosa peniana, frequências cardíaca e respiratória dentro da normalidade, temperatura retal $39,54^{\circ} \mathrm{C}$ e presença de estrutura arredondada de consistência firme durante palpação abdominal. Posteriormente, foi realizado exame ultrassonográfico o qual indicou a presença de estrutura hiperecoica regular, promotora de sombra acústica posterior, medindo cerca de 24,0mm em seu maior eixo, sugestivo de cálculo vesical (Figura 1). Além do exame ultrassonográfico, foi realizada radiografia em projeções látero-lateral e dorso ventral, a qual identificou a presença de estrutura radiopaca e bem delimitada medindo $25,1 \mathrm{~mm}$ de comprimento, localizada em topografia de vesícula urinária, não sendo observadas alterações em parênquima e topografia renal (Figuras 2 e 3 ).

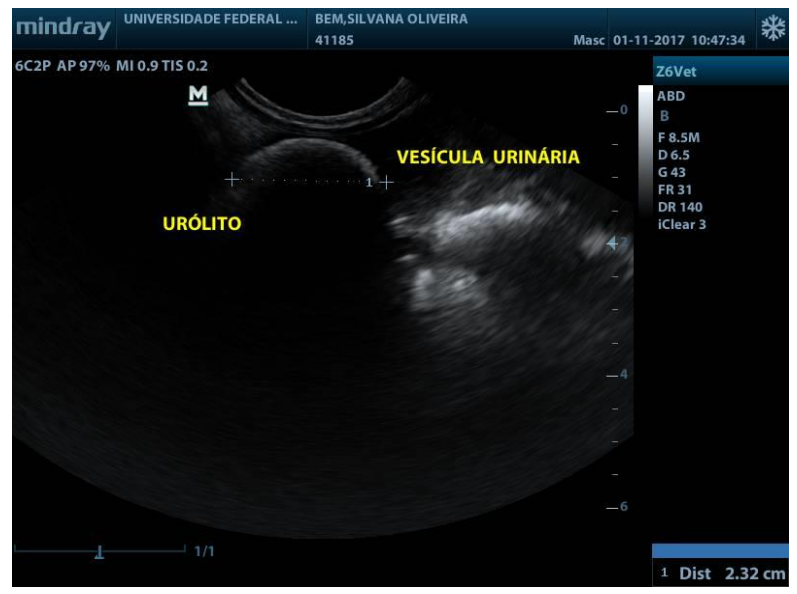

Figura 1. Exame ultrassonográfico de coelho (Oryctolagus cuniculus) apresentando estrutura hiperecoica (urólito) promotora de sombra acústica em bexiga (vesícula urinária).

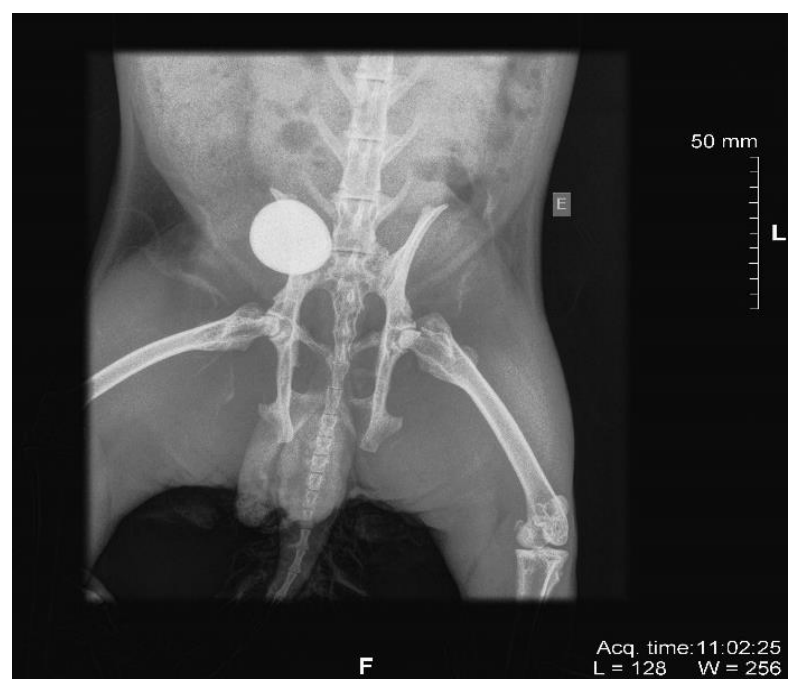

Figura 3. Exame radiográfico de coelho (Oryctolagus cuniculus) em projeção dorso-ventral urólito em bexiga.
A partir da anamnese, histórico e exames de imagem, concluiu-se que o caso tratava-se de cistolitíase, sendo, portanto, indicada cirurgia de cistolitectomia para sua resolução. A indução anestésica foi realizada utilizando associação de cloridrato de cetamina $10 \%$ e midazolam $(5 \mathrm{mg} / \mathrm{mL})$ nas doses de 20 e $1 \mathrm{mg} / \mathrm{kg}$, respectivamente, por via intramuscular profunda no músculo quadríceps. Após diminuição dos reflexos palpebrais e miorrelaxamento, foi realizado acesso venoso na veia marginal da orelha direita (Figura 4) para instituição da fluidoterapia transoperatória com o paciente mantido em plano anestésico com isofluorano administrado em máscara de oxigênio acoplada ao focinho (Figura $5)$.

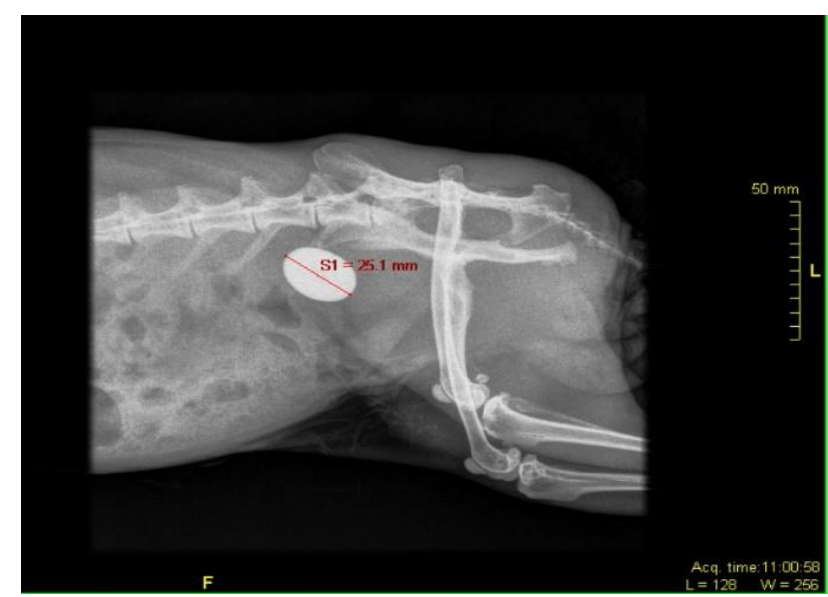

Figura 2. Exame radiográfico de coelho (Oryctolagus cuniculus) em projeção látero-lateral apresentando urólito com cerca de $25,1 \mathrm{~mm}$ de comprimento (S1) em bexiga.

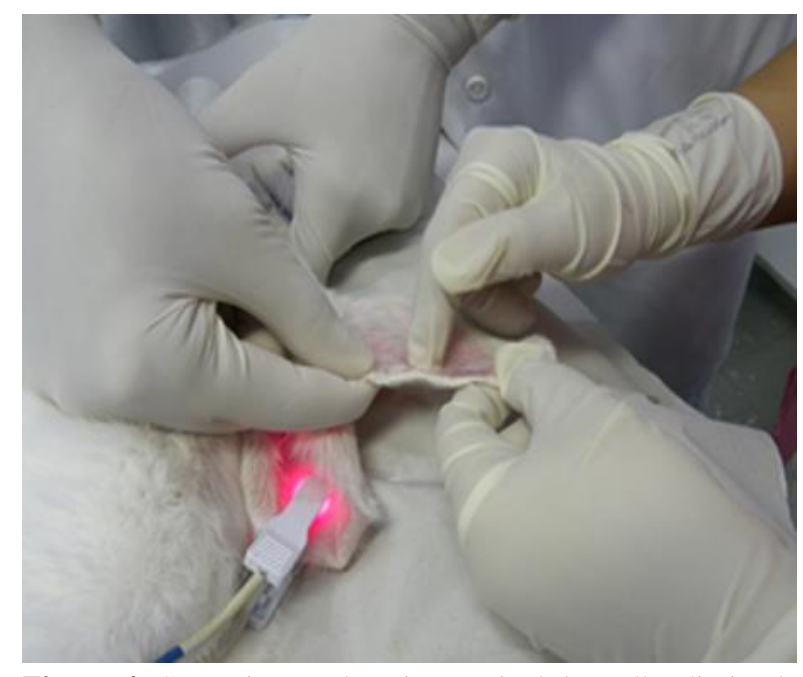

Figura 4. Cateterização da veia marginal da orelha direita de coelho (Oryctolagus cuniculus) para instituição de fluidoterapia parenteral transoperatória. 
Após tricotomia e antissepsia com Digluconato de Clorexidine 2\% e iodopovidona da região abdominal ventral, os campos cirúrgicos foram colocados (Figura 6) e o instrumental cirúrgico estéril foi devidamente organizado. Realizou-se incisão com lâmina de bisturi $\mathrm{n}^{\circ} 23$ da cicatriz umbilical ao púbis (Figura 7) para ter acesso à bexiga. Após exposição e isolamento da vesícula urinária, foram colocadas suturas de sustentação (Figura 8) para facilitar a manipulação do órgão e evitar extravasamento de urina. $\mathrm{O}$ conteúdo urinário foi puncionado em região lateral esquerda (Figura 9) com agulha e seringa estéreis, sendo encaminhado para posterior urinálise. Em seguida foi realizada incisão em região lateral esquerda da bexiga (Figura 10), uma vez que as faces dorsal e ventral apresentavam vasos sanguíneos calibrosos e sinuosos. A vesícula vazia facilitou a visualização do urólito, o qual foi retirado (Figura 11) e encaminhado para análise laboratorial.

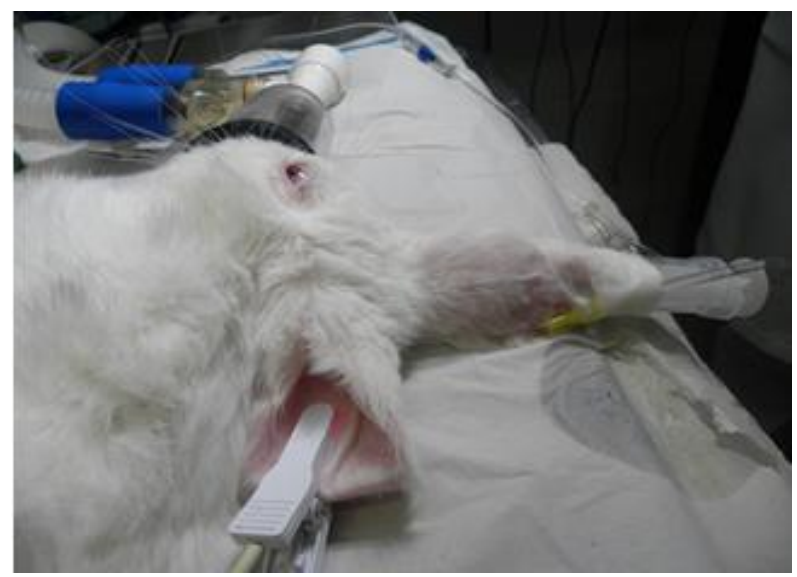

Figura 5. Manutenção do plano anestésico de coelho (Oryctolagus cuniculus) com isofluorano administrado em máscara de oxigênio acoplada ao focinho.

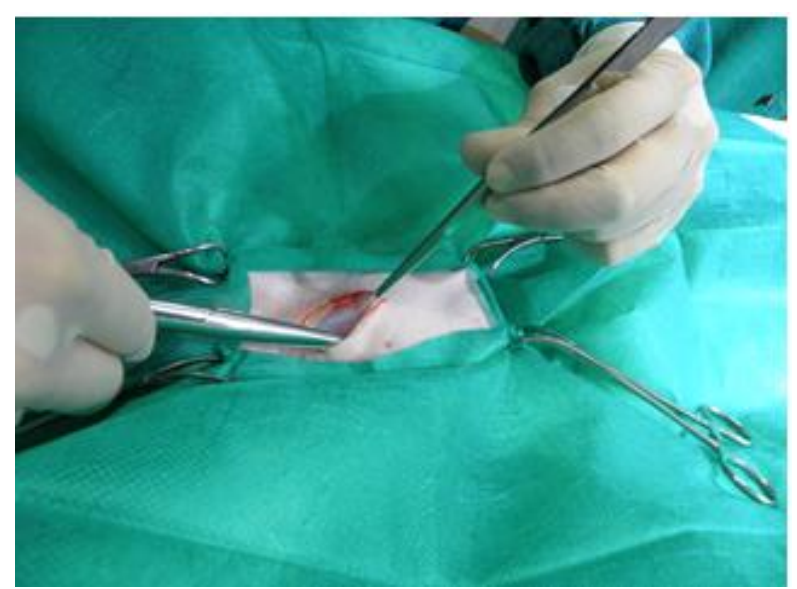

Figura 7. Incisão e divulsão da camada subcutânea do umbigo até o púbis para acesso à cavidade abdominal em coelho (Oryctolagus cuniculus).
Em seguida, foi realizada lavagem da bexiga e da uretra com auxílio de equipo (Figura 12) e sonda uretral estéreis contendo solução fisiológica $0,9 \%$, a fim de liminar qualquer resíduo de microcálculos presentes no trato urinário. $\mathrm{Na}$ sequência, as camadas seromusculares da bexiga foram suturadas (Figura 13) utilizando-se fio cirúrgico de poliglecaprone 4-0 em padrão contínuo com duas linhas de suturas invertidas, primeiramente em padrão Cushing seguido de padrão Lembert. Após verificar a ausência de qualquer extravasamento através da sutura ou de sinais de hemorragia, a camada muscular da cavidade abdominal foi suturada (Figura 14) utilizando-se fio não-absorvível 2-0 em padrão Sutan, seguida de sutura da camada subcutânea utilizando-se fio absorvível 4-0 em padrão simples contínuo e, finalmente, dermorrafia com fio absorvível 3-0 em padrão Wolff.

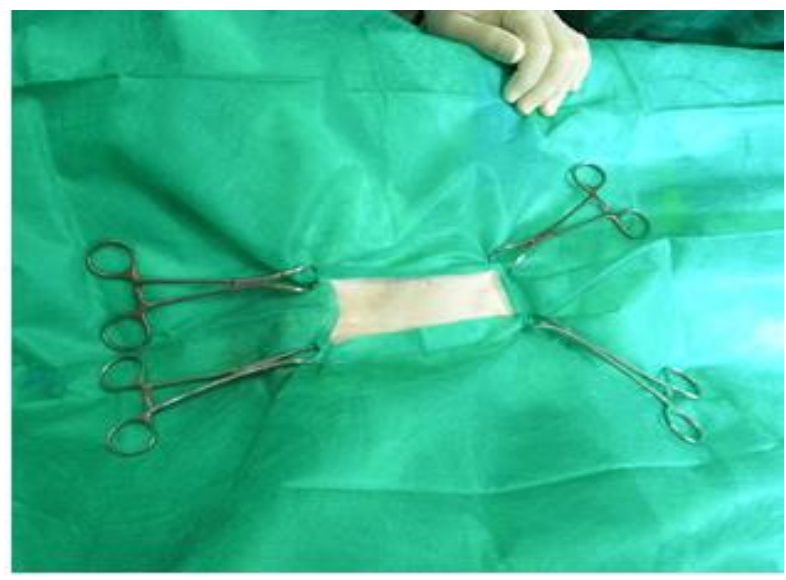

Figura 6. Colocação dos panos de campo estéreis para cirurgia de cistolitectomia em coelho (Oryctolagus cuniculus).

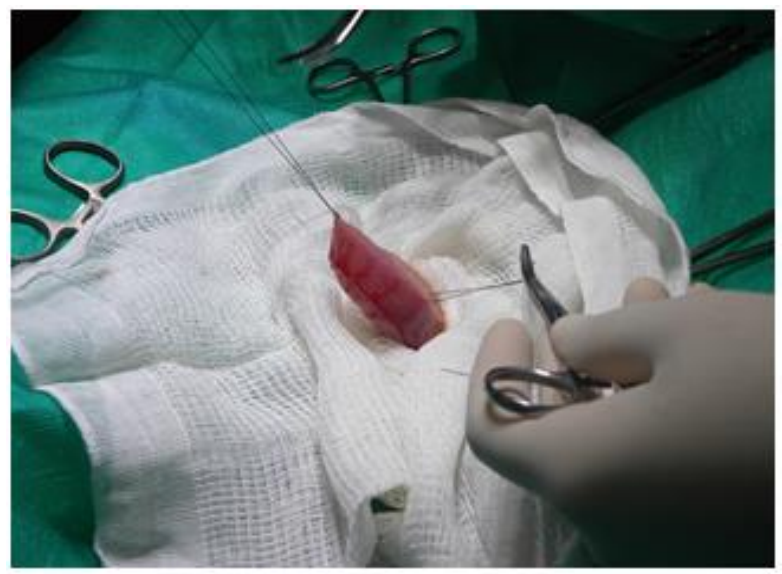

Figura 8. Colocação de suturas de sustentação na parede da vesícula urinária em coelho (Oryctolagus cuniculus). 
Para o pós-operatório foi prescrito Enrofloxacino e Cetoprofeno nas doses de $10 \mathrm{mg} / \mathrm{kg}$ e $1 \mathrm{mg} / \mathrm{kg}$, respectivamente, por via oral por quatro dias, além de limpeza da ferida operatória com solução de Digliconato de Clorexidine (2\%) e aplicação de curativo para proteção da lesão. Como medicação analgésica, foi prescrita administração de Cloridrato de Tramadol na dose de $1 \mathrm{mg} / \mathrm{kg}$, por via oral, por 3 dias. Foi recomendada, ainda, adequação da dieta com diminuição da quantidade de ração pela metade, associado a soro caseiro no volume de 1 litro por dia.

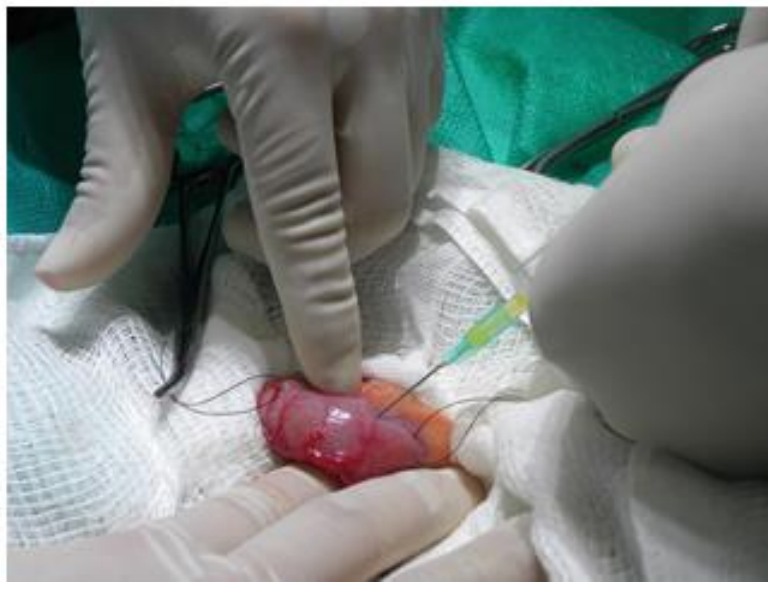

Figura 9. Punção do conteúdo urinário contido no interior da vesícula urinária para posterior urinálise em coelho (Oryctolagus cuniculus).

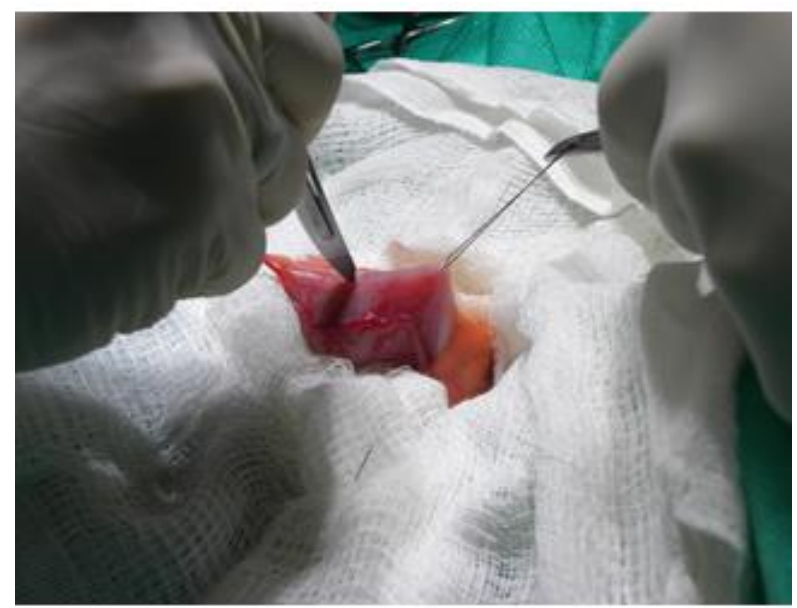

Figura 10: Incisão em região lateral esquerda da vesícula urinária para acesso ao conteúdo interno em coelho (Oryctolagus cuniculus).

A urina colhida foi analisada, sendo identificado $\mathrm{pH}=8,0$, densidade $=1014$, presença de albumina, hemoglobina, raras células epiteliais de descamação, piócitos, hemácias e raros cilindros granulosos. O cálculo retirado apresentava forma ovalada, coloração marrom escuro, superfície porosa, consistência pétrea, pesava $9,65 \mathrm{~g}$ e media
$2,0 \times 1,4 \mathrm{~cm}$ em seu maior e menor eixo, respectivamente. Quanto à composição química, foi identificada presença de carbonatos $(+++)$, oxalato $(+)$, fosfato $(+)$, cálcio $(+)$ e amônio $(+)$.

Após dez dias de operado, o animal voltou ao hospital para reavaliação apresentando melhora do quadro geral, normúria e retorno do apetite.

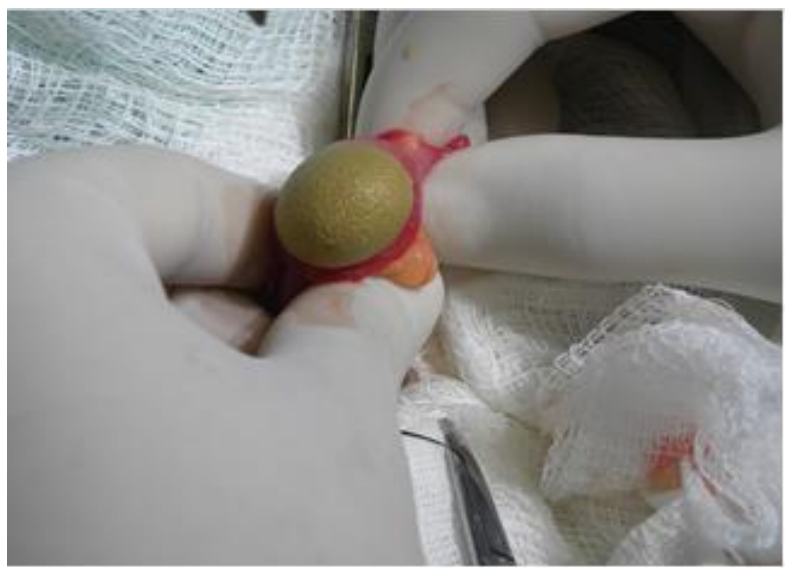

Figura 11. Exposição do urólito através da incisão na parede da vesícula urinária em coelho (Oryctolagus cuniculus).

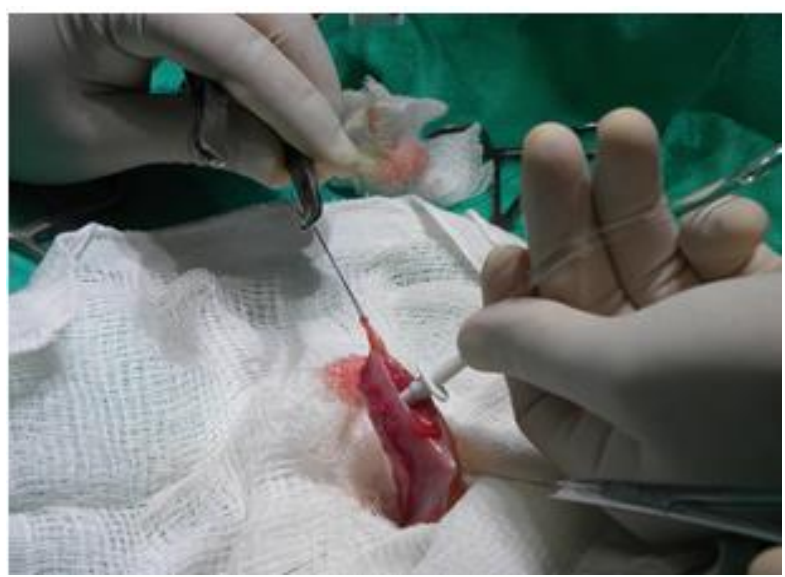

Figura 12. Lavagem da bexiga e uretra com auxílio de equipo contendo solução fisiológica $0,9 \%$ em coelho (Oryctolagus cuniculus).

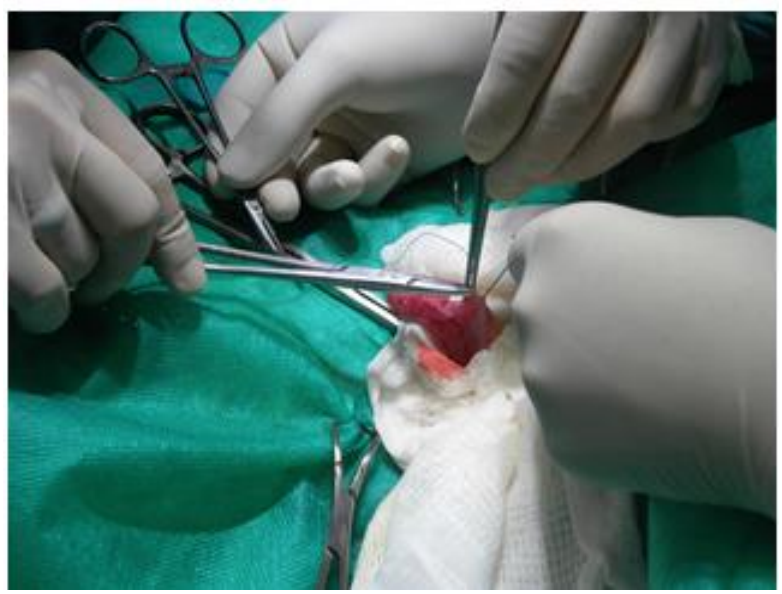

Figura 13. Sutura das camadas seromusculares da bexiga com fio absorvível 4-0 em padrão contínuo. 


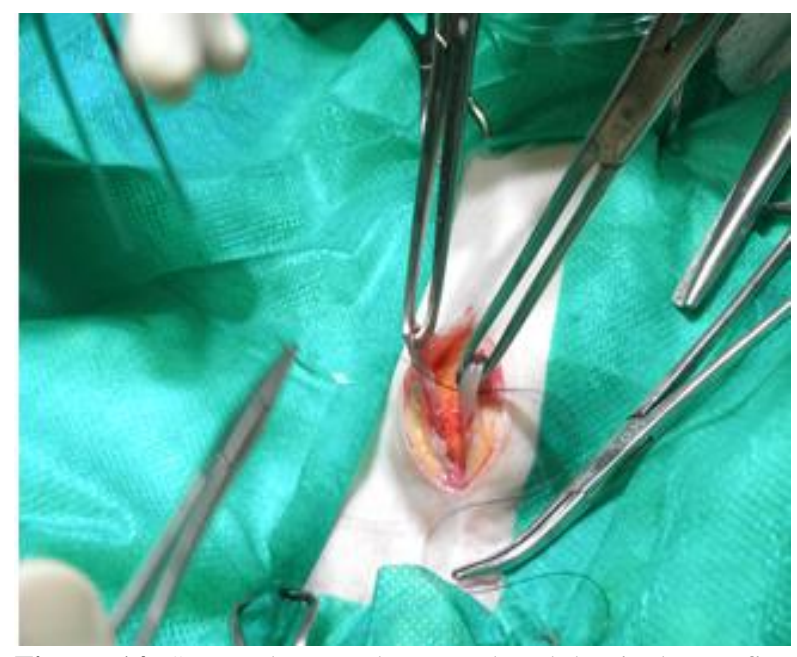

Figura 14. Sutura da camada muscular abdominal com fio não absorvível 2-0 em padrão Sutan em coelho (Oryctolagus cuniculus).

\section{Discussão}

Os coelhos podem ter uma combinação de cálculos císticos, uretrais, ureterais ou renais (Pare e Paul-Murphy, 2003). Apesar do que é conhecido sobre o metabolismo do cálcio em coelhos, a causa exata ou as causas da formação não são compreendidas (Fisher, 2006), porém, é um consenso entre vários autores que a formação de urólitos está principalmente relacionada ao elevado consumo de dieta seca e à ingestão insuficiente de água, levando à precipitação da urina, naturalmente rica em minerais (Quinton, 2005; Vilardo, 2007). No presente relato, a alimentação do paciente limitava-se à ração comercial seca, o que pode ter contribuído para uma maior precipitação de minerais na urina e consequente formação de cálculo.

De acordo com Fisher (2006), os sinais clínicos da urolitíase podem incluir letargia, diminuição do apetite, perda de peso, anúria, estrangúria, hematúria, postura arqueada e bruxismo, indicando dor abdominal. No presente relato, foi possível identificar a presença de estrutura firme em região abdominal que, associada aos sinais de hematúria e informações da anamnese, conduziram ao diagnóstico provisório de urolitíase vesical, o qual foi evidenciado nos exames de imagem. Sendo assim, os sinais clínicos apresentados pelo animal foram importantes para direcionar a conduta clínica e a suspeita de doença do trato urinário, visto que são comuns em quadros de urolitíase a presença de hematúria, apatia, anorexia e desidratação (Harcourt-Brown, 2002; Quinton, 2005; Vilardo, 2007), sinais também identificados neste caso.

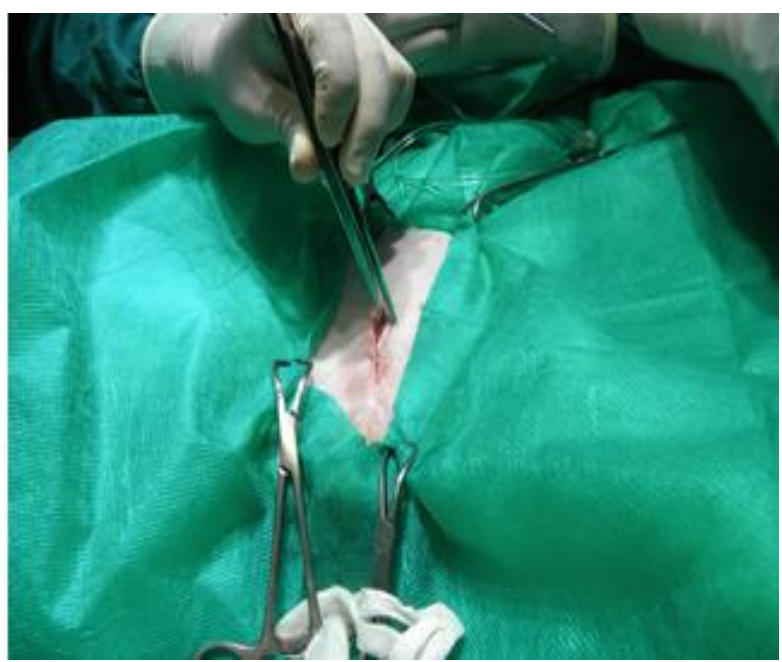

Figura 15. Dermorrafia com fio não-absorvível 2-0 em padrão Wolff em coelho (Oryctolagus cuniculus).

A realização da radiografia foi importante não apenas para identificar a presença do urólito, mas também para diferenciar de lama urinária, igualmente comum em coelhos e que, futuramente, pode resultar em urólitos (Brown, 2011). Foi possível identificar a presença de um cálculo relativamente grande sendo, neste caso, indicado o tratamento cirúrgico (Brown, 2011).

$\mathrm{O}$ acesso à cavidade abdominal procedeu-se como recomendado por Fossum (2014), cuja técnica preconiza uma incisão nas camadas serosa, muscular e mucosa da vesícula urinária em sua região dorsal ou ventral, distante do trígono vesical e de grandes vasos. No entanto, no presente caso essas áreas apresentavam-se ricamente vascularizadas, sendo realizado o acesso lateral da bexiga. Os demais procedimentos seguiram as recomendações de Harcourt-Brown (2002) e Fossum (2014).

Da mesma forma que em outros mamíferos, a urinálise pode fornecer informações valiosas em relação ao estado do aparelho urinário (Melillo, 2007) dependendo das características da urina que, em coelhos, apresenta coloração de branco a castanho claro devido às quantidades elevadas de sedimento, densidade variando de 1.003 a $1.036 \mathrm{e}$ pH entre 8 e 9 (Melillo, 2007; Jekins, 2008). No presente relato, foi realizada análise físico-química da urina, a qual se mostrou dentro dos padrões de normalidade. Já a análise química do cálculo identificou a intensa presença de carbonato, possivelmente cristais de carbonato de cálcio, visto que este mineral é o componente mais comum encontrado em urólitos de coelhos domésticos (Harcourt-Brown, 2002). 
No tratamento das enfermidades do trato urinário inferior, é necessário, se possível, tentar reconhecer a causa primária e tratá-la (HarcourtBrown, 2002). Para dar conforto ao paciente, podese utilizar analgésicos, anti-inflamatórios não esteroides e, quando cistite estiver instalada, podese adicionar antibióticos, podendo ser prolongado para o pós-operatório. Após a remoção cirúrgica do cálculo, o paciente manteve o protocolo terapêutico com Cetoprofeno, Cloridrato de Tramadol e Enrofloxacino, fármacos amplamente utilizados para a espécie, segundo recomendações de Carpenter (2003) e Reusch (2006).

No presente relato, o paciente teve boa recuperação pós-operatória, fato que pode estar relacionado à adoção de protocolo analgésico, antiinflamatório e antibiótico adequado, baseado em informações atuais sobre terapêutica de lagomorfos Carpenter (2003) e Reusch (2006). Isto tudo, associado à adequação da dieta, pode ter favorecido a rápida e boa resolução do caso.

\section{Conclusão}

A conduta clínica associada ao tratamento cirúrgico neste caso foi eficaz para garantir a boa recuperação do paciente. Além disso, embora a literatura descreva o manejo e a técnica cirúrgica do paciente acometido por urolitíase, neste caso a abordagem foi diferente da utilizada rotineiramente, ressaltando a importância deste tipo de estudo na medicina veterinária.

\section{Conflito de Interesse}

Os autores descartam qualquer conflito de interesse.

\section{Agradecimentos}

À equipe de veterinários residentes e técnicos do HOVET-UFRA pelo apoio durante o tratamento do paciente.

\section{Referências}

Brown, C. Urolithiasis and cystotomy in the rabbit.

Lab Animal, 40(3): 73-74, 2011.
Carpenter, J.W. Lagomorpha (pikas, rabbits and hares). In: Fowler, M.E.; Miller, R.E. Zoo and wild animal medicine. $5^{\text {th }}$ ed. Philadelphia: W.B. Saunders, 2003. p. 410-419.

Chapman, J.A.; Flux, J.E.C. Introduction to the Lagomorpha. In: Alves, P.C.; Ferrand, N.; Hacklander, K. (Eds.). Lagomorpha biology: evolution, ecology, and conservation. $1^{\text {st }} \mathrm{ed}$. Heidelberg: Springer, 2008. p.1-9.

Fisher, P.G. Exotic mammal renal disease: Causes and clinical presentation. Veterinary Clinics Exotic Animal, 9(1): 33-67, 2006.

Fossum, T.W. Cirurgia de pequenos animais, $4^{\text {th }}$ ed. Rio de Janeiro: Elsevier, 2014. 1640p.

Harcourt-Brown, F. M. Textbook of rabbit medicine. $1^{\text {st }}$ ed. Oxford, UK: Reed Educational and Professional Publishing, 2002. 410p.

Jenkins, J.R. Rabbit diagnostic testing. Journal of Exotic Pet Medicine, 17(1): 4-15, 2008.

Melillo, A. Rabbit clinical Pathology. Journal of Exotic Pet Medicine, 16(3): 135-145, 2007.

Pare, J.A.; Paul-Murphy, J. Disorders of reproductive and urinary systems. In: Quesenberry, K.E.; Carpenter, J.W. Ferrets, rabbits and rodents: clinical medicine and surgery. $2^{\text {nd }}$ ed. Philadelphia: WB Saunders, 2003. p.183-193.

Quinton, J.F. Novos animais de estimação: pequenos mamíferos. São Paulo: Roca, 2005. 336p.

Redrobe, S. Calcium metabolism in rabbits. Seminars in Avian and Exotic Pet Medicine, 11(2): 94-101, 2002.

Reusch, B. Urogenital system and disorders. In: Meredith, A. Manual of Rabbit Medicine and Surgery. $2^{\text {nd }}$ ed. Telford Way UK: British Small Animal Veterinary Association, 2006. p.85-95.

Vilardo, F.E.S. Lagomorpha (Coelho, Lebre, Lebre-assobiadora). In: Cubas, Z.S.; Silva, J.C.R.; Catão-Dias, J.L. Tratado de animais selvagens - medicina veterinária. $1^{\mathrm{a}}$ ed. São Paulo: Roca, 2007. p.415-431. 